\title{
New media adoption and usage among Flemish youngsters
}

\author{
Schuurman Dimitri, Researcher, IBBT-MICT \\ Courtois Cédric, Researcher, IBBT-MICT \\ De Marez Lieven, Professor, Senior Researcher IBBT-MICT \\ Corresponding author: \\ Schuurman Dimitri \\ Dept. of Communication Sciences, MICT-IBBT \\ Ghent University \\ Korte Meer 7-9-11 \\ 9000 Gent, Belgium \\ Dimitri.Schuurman@UGent.be
}

T: +3292649154

F: +32926468 85 
Keywords: new media and ICT, adoption, usage, diffusion of innovations, domestication

\section{Abstract}

This article presents a study on the adoption and usage of new media among a representative sample of Flemish youngsters. Some major findings include the dominant role of computers and Internet in the media behavior of these youngsters, challenging traditional media such as TV and radio. However, the supposed popularity of mobile applications and gaming among youngsters was not universally present in our sample, which led us to look for different profiles within the data. Based on the adoption of new media technology and devices, the studied sample could be divided into four distinct profiles by means of a latent class analysis.

The first profile is the youngest and shows high adoption rates of new media devices and technology. Their usage is clearly oriented towards entertainment and includes gaming and various mobile applications. The second profile has a female and working profile with an average usage and adoption of new media. The usage is mostly professional and convenience-oriented in nature, without interest in gaming or mobile applications. The third profile is distinctively male and focuses its media usage on computer, Internet and mobile applications, but clearly show no interest in (mobile) gaming consoles. The fourth and final profile is the oldest and counts the least students. It is the least equipped in terms of new media. However, they are more likely to use their less advanced devices to their full potential. By this, this article challenges the stereotypical view of young people as 'homogenous mass' of early adopters of new media devices and technologies by showing that there are different types of media users and usage among youngsters.

\section{Introduction}

If you take into account the dazzling speed by which new devices and applications come to the market, it seems like new media technologies are taking over the command of the old media. These innovations introduce new media practices to the user, extending the consumption of media content 
beyond the borders of time and space. The introduction strategies are in most cases clearly oriented towards the younger segments of the population, as they are believed to be the most open to change. This results in a stereotypical and unidimensional representation of young people as active, media-hungry multi-taskers that want their media content anytime anywhere. However, a lot of innovations are prematurely put to sleep or do not reach the expected market share. Some recent examples include the disinterest of the user in mobile services such as MMS or mobile TV, despite a strong belief of the sector in the success of them (cf. e.g. Hsu et al., 2007; Schuurman et al., 2009).

Therefore, we believe it is necessary to keep track of the actual adoption and usage of new media technologies so that a nuanced image of the media behavior of young people can be constructed. Within this article, we present an analysis of the adoption and usage of media of Flemish youngsters (aged fifteen to thirty). The data come from a subset of 354 respondents from a representative survey on new media adoption and usage. In order to get a more nuanced view of the surveyed youngsters, a clustering based on the adoption of media devices was performed. This resulted in four distinct adoption profiles with each their specific media practices.

\section{Adoption diffusion vs. use diffusion}

Two major paradigms can be distinguished by which innovations tend to be studied: the diffusion of innovations (adoption diffusion) and the domestication of innovations (use diffusion). The former is the oldest and most studied of the two (Mahajan et al., 2000). Numerous studies have showed that in most cases the diffusion curve is S-shaped. This is caused by a slow take-off, followed by a strong increase (at the so-called 'tipping point'), and then slowing down again once a certain level of market saturation is reached (Rogers, 2003). Initially, this perspective assumed that the diffusion of innovations in a social system always follows a bell-shaped, normal distribution where five adoptercategories can successively be distinguished with fixed segment sizes (Rogers, 2003). More recently, these assumptions have been criticized, leading to alternative views on the diffusion, such as a

product or innovation specific adoption curve (cf. De Marez \& Verleye, 2004). Besides some 
modifications to the theory itself, there was also a lot of criticism regarding the supposed technological deterministic nature and the lack of attention to the eventual usage of the innovation (Robertson, 1984). This has led to the rise of a second paradigm: domestication. This perspective is closely related to the idea of the 'social shaping of technology'. Its point of view steered away from the traditional deterministic approaches which took for granted the character and direction of technological advance and put the focus on the content of technology and to the processes involved in innovation (Bijker, Law, 1992; Williams, Edge, 1996). Contributors to the domestication-approach argue that the ICT-innovation can be shaped by social factors such as class, gender, culture or lifestyle as well (Silverstone, Haddon, 1996). This process of integration within everyday's context is also known as 'domestication' and was initially based on a social deterministic point of view (Jankowski, Van Selm, 2001).

As is the case with most scientific dichotomous disputes, both paradigms were eventually considered as complementary, with the diffusion of innovations as the more quantitative tradition with the focus on acceptance and adoption decisions, and the domestication tradition as more qualitative with a focus on the usage and appropriation of technologies (Punie, 2000). It was also argued that both processes flow into each other and that only when both are completed, an innovation can be considered as a success (Boczkowski, 2004; Green, 2002). The dialectical approach, integrating insights from both research traditions, is referred to as the mutual shaping-stance. This has for instance triggered a successful translation from insights from the domestication-framework into quantitative research into the use diffusion of ICT-innovations (Shih, Venkatesh, 2004). This research focuses on the range and intensity of applications that is used on ICT-devices.

Regarding new media and ICT-content and devices, the convergence debate has also gained a lot of attention lately. Media content used to be highly dependent on a specific technology as the broadcasting, telecommunication, publishing and information technology industries were overall characterized by their 'silo structures', referring to their rigid separation (Dwyer, 2010). Nowadays, the (new) media are characterized by the blurring of lines between media and communications, 
which enables services that used to be provided in different physical ways to be delivered on multiple devices. This process of convergence shatters the tight relationship between a medium and its content. Due to the far-reaching process of digitization, media content has been increasingly the subject of convergence. The same was believed to be true for technology, where it was expected that different media consumption devices would converge into a single central device. However, this idea is now referred to as the 'black box fallacy', as an opposite trend is observed. Nowadays, there is a large variety of (compatible) devices available where users can use and consume multiple media services and a broad variety of content (Dwyer, 2010; Jenkins, 2006).

\section{Methodology}

The data for this study are taken from $\mathrm{IBBT}^{1}{ }^{1} \mathrm{~s}$ Digimeter. This is a survey, representative for Flanders, which is intended as a yearly monitor for the possession and usage of media and ICT. Respondents are surveyed using the $\mathrm{CAPI}^{2}$-method and the quota for representativity are based on the NIS/ADSEI ${ }^{3}$-statistics for 2008 and include province, sex and age. Only respondents of fifteen or older were selected. A weighted total of 1212 respondents filled out the survey from November 2009 through March 2010. The survey started with a list of 35 technologies. The respondents were asked if they had these technologies available in their homes. 'Home' was defined as the place where the largest part of their time was spent. Based on the answers for the initial 35 technologies, the respondents had to answer more specific questions regarding the usage of the media and ICT they owned. To avoid confusion regarding the interpretation of the surveyed technologies, a trained interviewer was always present to answer questions and every participant also had a booklet with illustrations and a short explanation about every surveyed technology or device.

\footnotetext{
${ }^{1}$ Interdisciplinary Institute for Broadband Technology, an independent research institute founded by the Flemish government to stimulate ICT innovation.

${ }^{2}$ Computer Assisted Personal Interview

${ }^{3}$ Nationaal Instituut voor de Statistiek (NIS) or Algemene Directie Statistiek en Economische Informatie (ADSEI)
} 
From this sample of 1212 participants all respondents younger than thirty were selected. This resulted in a representative subsample of 354 youngsters from fifteen to thirty. Still, we do not expect this group of youngsters to be a homogenous mass. Therefore, we extend the general description of youngsters as a whole with a latent class analysis of the adoption of (new) media technologies and devices on this sample. This technique allows for the induction of latent structures within categorical data. We apply the common strategy of iterating the analysis with an increased number of classes until a model fit is found. Trough out the article, these profiles of media adoption are further described in terms of socio-demographics and media usage.

\section{Results}

The subsample of youngsters (aged between 15 and 30) from the Digimeter consisted of 354 weighted cases. The socio-demographical statistics of the sample are given in table 1 . Thirty per cent of them are still teenagers, while the remaining 70 per cent are in their twenties. The majority of youngsters is still studying, living with parents/family and has a secondary school degree, although we can distinguish quite some variety in the different variables.

[insert table 1 here]

As argued in the methodology section, a latent class analysis is performed on the sample of youngsters. A four-cluster model appeared the most parsimonious solution, yielding a satisfactory model fit $\left(L^{2}(299)=332.52, p=.09\right)$. Table 2 summarizes the probabilities of adoption profile members to own specific media technologies.

[insert table 2 here]

\section{General sample description}


Before describing the inducted profiles, we discuss the general sample. According to the figures in table 2 , youngsters own a variety of different media devices and technologies. Virtually everyone has a mobile phone, and only very small minorities do not have a TV, computer or Internet connection. Gaming consoles have crossed the 50 per cent penetration threshold, outgrowing their niche-status. Mobile devices are also very popular with 86 per cent having a laptop, 87 per cent having an MP3player and 43 per cent having a mobile game console. The fact that almost four out of ten have a mobile phone with Internet possibility or even a smartphone only adds to this claim.

Within the survey, respondents were also asked to indicate how much time they spend on the different surveyed media. This was measured by a eight-point scale ranging from 0 (= none) tot 7 (>6 hours). Figure 1 gives the average time spent for these different media amongst young people. Table 3 shows the percentages of non-users $($ score $=0$ ) for each media activity.

[insert figure 1 here]

[insert table 3 here]

Young people clearly spend most of their media time on the computer and on the Internet. The percentage of non-users is also the lowest for computer and internet during the week. This means that computer and internet have surpassed TV as the dominant medium amongst youngsters, although the time spent on TV viewing remains quite high. Listening to music also constitutes a large part of the youngsters' media usage as both listening to the radio and to their personal music collection have the sixth and seventh average score. The gaming items clearly have the lowest score.

Table 3 with the percentages of non-users helps to further explain the figure. For radio and collection, the percentages non-users are higher than for internet, computer and TV, but they remain well below 20 per cent. For gaming on different platforms, the numbers of non-users increase dramatically. This causes that these media take a significantly smaller proportion of the youngsters' 
media time in comparison with the others, although for gaming on computer the users outnumber the non-users. This indicates that gaming is outgrowing its niche status, but clearly rejects the popular view of all young people being a gamer.

Besides the time spent on different media, the respondents were also surveyed regarding their application usage on computer, internet and mobile phone. In table 4 the percentages are shown of the survey participants using the mentioned applications at least once a week. The applications are ranked from high to low. Table 4 gives also the statistics for significant differences of these applications for the adoption profiles. These differences are reviewed in the next section.

[insert table 4 here]

For computer, the most popular applications are using the Internet and e-mail, both with more than nine out of then doing this at least weekly on their computer. Listening to music and using a word processing program come in third and fourth place with more than three out of four youngsters engaging in these activities on a weekly basis. Gaming completes the top five with a score over fifty per cent, confirming the results from the analysis of the media usage. The practice of (illegal) copying is apparently quite common among young people, as more than one out of three copies music and more than one out of five copies movies on a weekly basis. The copying of movies is even almost twice as popular as watching movies on the computer.

The most popular activity on the Internet is searching for information, followed by using webmail and watching other people's profiles on social networking sites. Watching videos, following the news and looking at online photos are also weekly activities for about three out of four youngsters. Chatting, reading forums and using e-banking also score more than fifty per cent, while all more 'active' and 'participative' applications score below this treshold. Editing one's own profile is done by just over one out of three on a weekly basis, posting on a forum and downloading software score just under 
two out of three. Watching videos was slightly more popular than watching photos, however uploading photos clearly beats uploading videos with respectively one out of four versus one out of ten doing this on a weekly basis. Online buying and selling remains a rather marginal and niche activity amongst young people.

When looking at the mobile applications, we see that young people clearly prefer texting to calling. The majority of more than six out of ten sends more than three text messages a day, whereas only fifteen per cent makes more than three phone calls a day. One out of four sends between one and three text messages a day, twelve percent less than one a day and less than one per cent never sends text messages. More than three per cent never makes phone calls with a mobile phone, roughly half of the sample does this less than once a day and about a third makes one to three calls a day.

Although mobile applications are traditionally associated with young people, the results from our survey do not fully support this assumption. More than one third of all surveyed young people indicate that they do not use any mobile applications, besides calling and texting. For the remaining 62 percent the top three applications are taking pictures, listening to MP3s and playing games. Almost one out of five uses the mobile phone at least once a week to surf the Internet and fourteen percent to email, which indicates that mobile Internet appeals to a quite large niche of young people. FM radio accounts for only sixteen per cent, which indicates that young people tend to prefer listening to music of their own taste as listening to MP3s scores more than twice as much. The popularity of MMS, chatting and watching mobile TV/video remains very low.

These general results draw up an image of young people having a lot of new media devices and technologies at their disposal, although they do not use these all in the same manner. Some activities and applications are quite generally popular, while others appeal to different niches. A large group uses its mobile phone for applications beyond calling and texting, but a substantial part of the youngsters however rejects the use of mobile applications. In the remainder of this article we will 
look closer into the four clusters, extracted from the subgroup of young people, in order to get a more detailed and clear-cut image of their media usage.

\section{Adoption profiles' description}

\section{Adoption profile 1}

The first cluster is the largest with 55 per cent of all youngsters from the sample. With the highest percentages of teenagers and students, this segment has the youngest profile of all four. People within this profile have the highest probability of having iDTV (almost seven out of ten) and show the highest scores on week and weekend TV viewing. With three out of four, the first segment also has the highest probability for having both a desktop and a laptop at their disposal. This results in a high score for computer and internet usage, but significantly lower than the third adoption profile.

When looking at the computer applications that are used on a weekly basis, only spreadsheets score below the sample-average. For listening to music, gaming, and the copying of music and movies this profile has the highest percentages, indicating that they use the computer mostly for the consumption and facilitation of media entertainment content, which is also reflected in the highest scores for time spent on computer gaming. The same holds true for Internet applications, as within this profile we notice the highest percentage of weekly users for the following applications: webmail, photo viewing and downloading of podcasts. This segment is the most active and participative of all four in terms of online applications, as they have the highest scores for photo and video posting, online studying, editing of one's own blog and online buying.

We already mentioned the high number for computer gaming for this cluster, but this is also the case for console and mobile gaming as this segment has the highest probabilities of all segments for having both gaming and mobile gaming consoles, and also the highest usage scores for both. For portable consoles, roughly one out of three plays games during the week and during the weekend. 
People in this segment have just over one out of two chances for owning a basic mobile phone, one out of three for an Internet phone and 16 per cent for a smartphone, roughly dividing this segment into fifty percent basic mobile phone owners and fifty percent with more advanced devices that provide the possibility to go online. However, not all fifty per cent of this second category uses this option as less than a third of the youngsters from this profile has a subscription for mobile Internet and less than one out of four indicates that they surf the Internet on their mobile phone on a weekly basis. However, the majority of youngsters from this profile (more than seven out of ten) uses at least some mobile applications on a weekly basis.

The five most popular applications are in line with the general top five and include taking pictures, listening to MP3s, gaming, surfing the Internet and listening to FM radio. The fact that listening to MP3s is more than twice as popular as listing to FM radio, can also be witnessed when looking at the music consumption variables, as listening to one's own music collection scores higher than listening to the radio. Finally, the percentages for the first three applications are much higher than the average percentage of the total sample and confirm the view that this profile tends to use media mostly for entertainment purposes.

\section{Adoption profile 2}

This second largest segment contains just over a quarter of the surveyed youngsters. It has a distinctively 'female' (more than 60 per cent) and less student profile, with an overrepresentation of white collar workers in comparison with the total sample.

The scores for TV viewing are below average, but in the weekend viewing is considerably higher than during the week. Although the probabilities of having a computer and Internet are very high and are more or less up to par with the first and third profile, the usage scores for computer and Internet are significantly lower. For the different surveyed computer applications, this segment scores rather average. However, for three applications a much lower percentage of youngsters was found as a regular user: listening to music, and copying music and movies. For Internet applications, this cluster 
has the highest score of all four for looking for information and online selling. Following the news, ebanking and webmail score significantly above average, while chatting, commenting on blogs and downloading software have percentages below the average. This leads us to conclude that this profile uses the computer and Internet as a convenience tool for more practically oriented matters, but is not that interested in entertainment or more active participation through the web.

This is confirmed when looking at gaming. This segment seems to have almost no interest in it, as the probability of this segment for having a game console or a mobile console are the lowest for all groups. This is also highlighted by the high percentages of non-users. For console gaming, only five per cent games during the week and seven per cent during the weekend, and for mobile gaming, the percentage of users during both the week and the weekend is even equal to zero per cent.

With 99 per cent this segment clearly has the highest probability for having a basic mobile phone which implies that hardly anyone has a more advanced mobile phone. This is also reflected in the usage of mobile applications as this segment has the highest proportion (more than six out of ten) of youngsters not using any mobile applications at all. Only taking pictures and listening to MP3s are used by more than one out of ten on a weekly basis. Although this segment has a rather high probability of having an mp3-player, it has the lowest score for listening to a personal music collection. In contrast, listening to radio is clearly preferred, as the usage score is above average.

\section{Adoption profile 3}

With twelve per cent, this is the second smallest segment with a dominantly 'male' profile (almost two out of three). This segment has the highest probability of not having a TV, which is also apparent in the number of non-users. This helps to explain that the scores for week and weekend TV viewing are both below average, with even the lowest score of all segments for week viewing. The mediapriorities of this profile are clearly in the area of computer and Internet usage, as the highest scores for computer, Internet week and Internet weekend can be found here. This segment also has the highest probability of having a laptop (99 per cent). 
This cluster has the highest percentage of weekly users for the following computer applications: Internet, email, word processing and spreadsheets. Interestingly, this profile counts the smallest proportion of youngsters for watching movies and pictures on the computer. Regarding Internet applications, this segment has the highest percentages for the majority of internet applications, including following the news, e-banking, skyping, chatting, watching videos, reading and posting on forums, editing one's profile and watching others profiles, inspecting tags, commenting on a blog and downloading software. This cluster has the lowest percentage for online studying.

Regarding gaming, this profile runs in parallel with the second profile. The probabilities of having a gaming console or a mobile console are low, and the usage is even lower. This is the most obvious for mobile gaming. Although there is a close to ten percent chance for people within this segment of owning a mobile console, no one uses one.

A different story applies regarding mobile phones. This segment has the highest probability for owning an Internet phone or a smartphone, displaying the most advanced behavior in term of mobile applications compared to the other clusters. Almost half of this cluster uses the mobile phone for Internet from time to time, and one out of three even has a mobile Internet subscription. Not surprisingly, youngsters in this profile are also at the forefront of mobile applications usage. Only a 15 per cent minority does not use any, while the rest shows a wide variety of mobile applications usage. The top three applications score above 50 per cent: taking pictures, surfing and listening to MP3s. Three other applications are used by more than one out of three on a weekly basis: gaming, synchronizing agenda and email. Finally, this segment is most likely to listen to their own music collection, for instance with an MP3-player for which they have the second highest probability of having one, and is least likely to listen to the radio. When comparing this profile with the first adoption profile, the computer, internet and mobile application usage tends have a more professional and informational character and is clearly less entertainment-oriented. Computer and 
Internet usage is even more intense than was the case for the first profile, while TV is used here the least of all profiles.

\section{Adoption profile 4}

The last adoption profile is clearly the smallest with only $6 \%$, but with the most diverging profile of all four. This group has the 'oldest' (90 per cent is twenty or older) and counts the least students. There is however a large overrepresentation of blue collar workers and the proportion of unemployed it twice the one in the general sample. In comparison with the other clusters, this group is the least equipped in terms of new media devices and technology, but also uses the technologies it has quite intensively.

This segment has the highest probability of users with analogue cable TV and the lowest probability of having iDTV, despite still amounting to 25 per cent. Despite the largest number of non-users, this segment has an average score for watching TV, which implies that the people who do watch TV spend a lot of time on it. This is also the only segment where the score for TV viewing during the weekend is lower than for weekdays.

It is also the only profile with a large proportion of non-computer and non-Internet users, which is for the largest part caused by the high probabilities of not having a computer and of not having an Internet connection. This is also reflected by the low scores for computer and Internet usage and by the low scores for all computer and Internet applications. However, this segment has the second highest probability of having a game console and a portable console, which also results in the second highest score for both console and mobile gaming. It is striking that during the week, youngsters within this cluster watch more TV than during weekends, while during weekends they play more games on (mobile) consoles than during the week.

This is the only segment that has a slight chance of not having a mobile phone. In terms of mobile applications, this profile can be compared to the second, as the majority does not use any at all. 
However, for some applications the percentages of weekly users are higher than for the second segment, such as taking pictures, listening to MP3s and FM radio, and making videos. Considering music, this cluster has the highest score for radio. Moreover, despite the lowest probability of all segments for having an MP3-player, the score for listening to one's own music collection is not the lowest. This suggests that this profile uses its smaller variety of less advanced devices with a relatively larger intensity.

\section{Conclusion}

Within our representative sample of Flemish youngsters, it became apparent the adoption diffusion of some new technologies and devices such as computer, internet and a mobile phone are nearly heading towards one hundred per cent penetration. This resulted in a higher rate of use for computer and internet compared to traditional media such as television and radio, although all four media seem to occupy a significant proportion in the media usage of youngsters. Still, when looking into more detail, there are notable differences in the adoption rates of gaming and advanced mobile devices such as laptops and smartphones. The assumption that youngsters cannot be considered a homogenous mass became apparent through the finding that the studied sample could be divided into four distinct profiles based on their adoption of new media technology and devices by means of latent class analysis.

The first and most frequently appearing profile consisted of the most 'teenage'-youngsters who have an abundance of new media devices and technology at their disposal in their homes. Their usage is clearly oriented towards entertainment, and this becomes also apparent by the fact that this profile is the most likely to be a gamer, on (mobile) consoles as well as on the computer.

The second profile has the most female and a more active and working profile. This segment shows an average usage and adoption of new media, and displays a mostly professional and convenienceoriented usage. Gaming and mobile applications are both almost completely absent in their media 
adoption and usage. Instead, they tend to rely on the traditional media channels for entertainment purposes.

The third profile is distinctively male and focuses its media usage on computer, Internet and mobile applications, in favor of the traditional media. Youngsters within this cluster are at the forefront of the adoption and usage of advanced mobile phones, but clearly show no interest in gaming consoles. When comparing this profile with the first adoption profile, the computer, Internet and mobile application usage tends have a more professional and informational character and is clearly less entertainment-oriented. Computer and Internet usage is even more intense than was the case for the first profile, while TV is used here the least of all profiles.

The fourth and final profile has the oldest and least 'student'-character, being the least equipped in terms of new media devices and technology, but more likely to use the fewer and less advanced devices it has to their full potential. Media consumption focuses on TV, radio and gaming on (mobile) consoles, while computer, Internet and advanced mobile applications are for the most part absent in this cluster.

These findings challenge the stereotypical view of young people as early adopters and users of new media devices and technologies, but indicate that there are different types of media users and usage among young people. The high importance of computer and Internet in the media usage of youngsters can be seen as a more general finding, but gaming and mobile applications are only popular for specific profiles of young people. It also appears that adoption of new media devices or technologies does not necessarily imply new use practices, or even that they will be used often. The findings within this article also show that some but certainly not all young people are consuming their preferred media content independent of the device.

\section{References}

Bijker, W., Law, J. (eds.), 1992. Shaping Technology, Building Society. MIT Press, Cambridge. 
Boczkowski, P.J. 2004. The Mutual Shaping of Technology and Society in Videotex Newspapers: Beyond the Diffusion and Social Shaping Perspectives. The Information Society, 20, 255-267.

De Marez, L. \& Verleye, G., 2004. “ICT innovations today: making traditional diffusion patterns obsolete, and preliminary insight of increased importance", Telematics \& Informatics, pp. 235-260.

Dwyer, T. 2010. Media Convergence. Maidenhead: Open University Press.

Green, L., 2002. Communication, Technology and Society. London: Sage Publications.

Hsu, C., Lu, H., \& Hsu, H. 2007. Adoption of the mobile Internet: An empirical study of multimedia message service (MMS). The International Journal of Management Science, 35, 715-726.

Jankowski, N. \& Van Selm, M. 2001. ICT en samenleving. Vier terreinen voor empirisch onderzoek. In: Bouwman, H. (Ed.), Communicatie in de informatiesamenleving. Utrecht: Lemma, 217-249. Jenkins, H. 2006. Convergence Culture: Where old an new media collide. New York: New York University Press.

Punie, Y., 2000. Domesticatie van ICT. Adoptie, gebruik en betekenis van media in het dagelijkse leven: Continue beperking of discontinue bevrijding? Doctoraal proefschrift, Vrije Universiteit Brussel, Brussel. Robertson, T.S., 1984. Marketing's potential contribution to consumer behavior research: the case of diffusion theory. Advances in Consumer Research 11, 484-489.

Rogers, E. 2003. Diffusion of innovations (5th ed.). New York: The Free Press.

Schuurman, D., De Marez, L., Veevaete, P., Evens, T., 2009. Context and content for mobile television: integrating trial, expert and user findings. Journal of Telematics and Informatics, 26, 293-305.

Shih, C. \& Venkatesh, A. 2004. "Beyond Adoption: Development and Application of a Use-Diffusion Model", Journal of Marketing (68), 59-72. 
Silverstone, R. \& Haddon, L., 1996. 'Design and the domestication of information and communication technologies: technical change and everyday life', in R. Mansell and R. Silverstone (eds.)

Communication by Design, pp. 44-74. Oxford: Oxford University Press.

Williams, R., Edge, D., 1996. The Social Shaping of Technology. Research Policy, 25, 865-899.

\section{Tables \& figures}

Table 1

\begin{tabular}{|l|l|l|l|l|l|}
\hline Age & $\%$ & Sex & $\%$ & \multicolumn{2}{|}{} \\
\hline 10 's & $29.9 \%$ & Male & $53.4 \%$ & \multicolumn{2}{|}{} \\
\hline 20 's & $70.1 \%$ & Female & $46.6 \%$ & & $\%$ \\
\hline & & & & Profession & $10.2 \%$ \\
\hline Family & $\%$ & Degree & $\%$ & Blue collar worker & \\
\hline Single & $23.7 \%$ & University & $20.1 \%$ & White collar worker & $28.5 \%$ \\
\hline Single with kids & $2.3 \%$ & Higher & $22.9 \%$ & Management & $1.4 \%$ \\
\hline Living together & $19.8 \%$ & Secondary school & $43.5 \%$ & Self employ & $2.5 \%$ \\
\hline Living together with kids & $6.2 \%$ & Primary school & $10.5 \%$ & Student & $50.3 \%$ \\
\hline $\begin{array}{l}\text { Living with } \\
\text { parents/family }\end{array}$ & $48.0 \%$ & None & $3.1 \%$ & Unemployed & $4.8 \%$ \\
\cline { 5 - 6 } & & & & Other & $2.3 \%$ \\
\hline
\end{tabular}

Table 2

\begin{tabular}{|c|c|c|c|c|c|c|}
\hline & $\begin{array}{l}\text { Adoption } \\
\text { profile } 1\end{array}$ & $\begin{array}{l}\text { Adoption } \\
\text { profile } 2\end{array}$ & $\begin{array}{l}\text { Adoption } \\
\text { profile } 3\end{array}$ & $\begin{array}{l}\text { Adoption } \\
\text { profile } 4\end{array}$ & Wald & $R^{2}$ \\
\hline Cluster Size & 0.55 & 0.26 & 0.12 & 0.06 & & \\
\hline \multicolumn{7}{|l|}{ Indicators } \\
\hline Television (connection) & & & & & $32.77 * * *$ & .08 \\
\hline No TV & 0.00 & 0.02 & 0.18 & 0.14 & & \\
\hline Analogue connection & 0.30 & 0.53 & 0.25 & 0.54 & & \\
\hline Digital connection (not iDTV) & 0.02 & 0.07 & 0.20 & 0.06 & & \\
\hline Interactive digital connection & 0.68 & 0.37 & 0.37 & 0.27 & & \\
\hline & & & & & & \\
\hline
\end{tabular}




\begin{tabular}{|c|c|c|c|c|c|c|}
\hline Computer & & & & & $19.03^{*}$ & .11 \\
\hline No computer & 0.00 & 0.01 & 0.00 & 0.36 & & \\
\hline Only a desktop & 0.09 & 0.16 & 0.00 & 0.45 & & \\
\hline Only a laptop & 0.16 & 0.32 & 0.31 & 0.18 & & \\
\hline Both desktop and laptop & 0.75 & 0.51 & 0.69 & 0.01 & & \\
\hline Mobile phone type & & & & & 11.44 & .24 \\
\hline No mobile phone & 0.00 & 0.00 & 0.00 & 0.09 & & \\
\hline Basic device & 0.52 & 0.99 & 0.06 & 0.82 & & \\
\hline Internet device & 0.31 & 0.00 & 0.39 & 0.09 & & \\
\hline Smartphone & 0.16 & 0.01 & 0.55 & 0.00 & & \\
\hline Internet connection & & & & & $22.70 * * *$ & .30 \\
\hline Yes & 0.99 & 0.97 & 0.87 & 0.43 & & \\
\hline No & 0.01 & 0.03 & 0.13 & 0.57 & & \\
\hline Fixed game console & & & & & $28.85^{* * *}$ & .44 \\
\hline Yes & 0.82 & 0.10 & 0.18 & 0.63 & & \\
\hline No & 0.18 & 0.90 & 0.82 & 0.37 & & \\
\hline Mobile game console & & & & & $21.84^{* * *}$ & .44 \\
\hline Yes & 0.72 & 0.01 & 0.08 & 0.29 & & \\
\hline No & 0.28 & 0.99 & 0.92 & 0.71 & & \\
\hline MP3-Player & & & & & $26.13 * * *$ & .21 \\
\hline Yes & 0.97 & 0.80 & 0.87 & 0.37 & & \\
\hline
\end{tabular}




\begin{tabular}{|l|l|l|l|l|l|l|}
\hline No & 0.03 & 0.20 & 0.13 & 0.63 & & \\
\hline
\end{tabular}

Table 3

\begin{tabular}{|l|l|r|r|r|r|}
\hline Media & general & Cluster 1 & Cluster 2 & Cluster 3 & Cluster 4 \\
\hline TV week & $7.9 \%$ & $5.2 \%$ & $6 \%$ & $19.5 \%$ & $21.1 \%$ \\
\hline TV weekend & $5.6 \%$ & $2.6 \%$ & $2 \%$ & $17.1 \%$ & $31.6 \%$ \\
\hline Computer & $3.1 \%$ & $0.5 \%$ & $1 \%$ & $2.4 \%$ & $42.1 \%$ \\
\hline Internet week & $3.1 \%$ & $6.2 \%$ & $1 \%$ & $2.4 \%$ & $47.4 \%$ \\
\hline Internet weekend & $6.2 \%$ & $3.6 \%$ & $4 \%$ & $2.4 \%$ & $52.6 \%$ \\
\hline Console week & $70.3 \%$ & $52.1 \%$ & $95 \%$ & $95.1 \%$ & $73.7 \%$ \\
\hline Console weekend & $61.6 \%$ & $39.7 \%$ & $92 \%$ & $92.7 \%$ & $57.9 \%$ \\
\hline Portable console week & $80.8 \%$ & $66.0 \%$ & $100 \%$ & $100 \%$ & $89.5 \%$ \\
\hline $\begin{array}{l}\text { Portable console } \\
\text { weekend }\end{array}$ & $78.5 \%$ & & & & \\
\hline Computergames week & $47.2 \%$ & $38.1 \%$ & $62 \%$ & $36.6 \%$ & $84.2 \%$ \\
\hline $\begin{array}{l}\text { Computergames } \\
\text { weekend }\end{array}$ & $45.2 \%$ & $36.6 \%$ & $60 \%$ & $34.1 \%$ & $78.9 \%$ \\
\hline Radio & $16.1 \%$ & $18.0 \%$ & $11 \%$ & $14.6 \%$ & $26.3 \%$ \\
\hline Collection & $15.8 \%$ & $12.4 \%$ & $20 \%$ & $17.1 \%$ & $26.3 \%$ \\
\hline
\end{tabular}

Table 4

\begin{tabular}{|c|c|c|c|c|c|c|c|c|}
\hline COMPUTER & $\%$ & $X^{2}(9)$ & INTERNET & $\%$ & $X^{2}(9)$ & MOBILE & $\%$ & $X^{2}(9)$ \\
\hline Internet & $98.0 \%$ & $\begin{array}{l}142.275 \\
* * *\end{array}$ & Information & $94.8 \%$ & $\begin{array}{l}25.166 \\
* *\end{array}$ & Take pictures & $47.4 \%$ & $\begin{array}{l}32.751 \\
* * *\end{array}$ \\
\hline E-mail & $95.3 \%$ & $\begin{array}{l}62.164 \\
* * *\end{array}$ & Webmail & $85.8 \%$ & $\begin{array}{l}17.221 \\
*\end{array}$ & MP3 & $34.4 \%$ & $\begin{array}{l}37.927 \\
* * *\end{array}$ \\
\hline $\begin{array}{l}\text { Listen to } \\
\text { music }\end{array}$ & $83.7 \%$ & $\begin{array}{l}36.418 \\
* * *\end{array}$ & $\begin{array}{l}\text { View } \\
\text { profiles }\end{array}$ & $81.1 \%$ & 16.721 & Games & $26.1 \%$ & $\begin{array}{l}26.014 \\
* * *\end{array}$ \\
\hline $\begin{array}{l}\text { Word } \\
\text { processor }\end{array}$ & $76.7 \%$ & 14.739 & $\begin{array}{l}\text { Watch } \\
\text { videos }\end{array}$ & $77.9 \%$ & $\begin{array}{l}33.926 \\
* * *\end{array}$ & Surfing & $19.3 \%$ & $\begin{array}{l}58.492 \\
* * *\end{array}$ \\
\hline Gaming & $52.8 \%$ & $\begin{array}{l}23.897 \\
* *\end{array}$ & News & $76.5 \%$ & $\begin{array}{l}26.819 \\
* *\end{array}$ & FM radio & $15.9 \%$ & 5.021 \\
\hline $\begin{array}{l}\text { Watch } \\
\text { pictures }\end{array}$ & $37.6 \%$ & 10.794 & $\begin{array}{l}\text { Watch } \\
\text { pictures }\end{array}$ & $74.7 \%$ & 10.377 & $\begin{array}{l}\text { Synchronizing } \\
\text { agenda }\end{array}$ & $14.5 \%$ & $\begin{array}{l}32.030 \\
* * *\end{array}$ \\
\hline Spreadsheet & $37.3 \%$ & $\begin{array}{l}31.125 \\
* * *\end{array}$ & Chatting & $70.6 \%$ & $\begin{array}{l}21.903 \\
*\end{array}$ & Email & $13.6 \%$ & $\begin{array}{l}29.093 \\
* * *\end{array}$ \\
\hline Copy music & $37.3 \%$ & $\begin{array}{l}31.990 \\
* * *\end{array}$ & Read forum & $55.5 \%$ & $\begin{array}{l}29.187 \\
* *\end{array}$ & $\begin{array}{l}\text { Shooting } \\
\text { videos }\end{array}$ & $13.4 \%$ & $\begin{array}{l}11.008 \\
*\end{array}$ \\
\hline Copy movie & $21.3 \%$ & $\begin{array}{l}19.178 \\
*\end{array}$ & E-banking & $52.9 \%$ & $\begin{array}{l}20.392 \\
*\end{array}$ & MMS & $6.8 \%$ & 0.627 \\
\hline \multirow[t]{4}{*}{ Watch movie } & $12.2 \%$ & $\begin{array}{l}33.467 \\
* * *\end{array}$ & Tags & $35.5 \%$ & $\begin{array}{l}17.901 \\
*\end{array}$ & Chatting & $6.0 \%$ & $\begin{array}{l}11.507 \\
*\end{array}$ \\
\hline & & & Edit profile & $35.5 \%$ & 14.340 & $\begin{array}{l}\text { Watch } \\
\text { TV/video }\end{array}$ & $4.5 \%$ & $\begin{array}{l}8.375 \\
*\end{array}$ \\
\hline & & & $\begin{array}{l}\text { Post } \\
\text { forum }\end{array}$ & $32.8 \%$ & $\begin{array}{l}25.208 \\
* *\end{array}$ & & & \\
\hline & & & Download & $32.0 \%$ & 40.586 & mobile & $37.5 \%$ & 42.936 \\
\hline
\end{tabular}




\begin{tabular}{|l|l|l|l|l|l|l|l|l|}
\hline & & & software & & $* * *$ & applications & & $* * *$ \\
\hline & & $\begin{array}{l}\text { Add } \\
\text { pictures }\end{array}$ & $24.7 \%$ & 13.307 & & $\%$ & $X^{2}(9)$ \\
\hline & & Skype & $18.0 \%$ & 14.376 & No sms & $0.3 \%$ & 23.880 \\
& & & $\begin{array}{l}\text { Comment } \\
\text { on blog }\end{array}$ & $16.6 \%$ & 11.338 & $<1$ sms/day & $11.9 \%$ & $* *$ \\
\hline & & $\begin{array}{l}\text { Online } \\
\text { studying }\end{array}$ & $14.0 \%$ & 20.822 & $1-3$ sms/day & $25.0 \%$ & \\
\hline & & Edit blog & $11.6 \%$ & 11.806 & $>3$ sms/day & $62.8 \%$ & \\
\hline & & Post video & $9.9 \%$ & 28.824 & & & \\
\hline & & & $\begin{array}{l}\text { Download } \\
\text { podcast }\end{array}$ & $9.9 \%$ & 26.245 & No phone calls & $3.4 \%$ & 15.073 \\
\hline & & $\begin{array}{l}\text { Online } \\
\text { buying }\end{array}$ & $6.4 \%$ & 4.049 & $<1$ call/day & $48.0 \%$ & \\
\hline & & $\begin{array}{l}\text { Online } \\
\text { selling }\end{array}$ & $4.9 \%$ & 10.035 & $1-3$ call/day & $33.8 \%$ & \\
\hline & & Sms & $4.9 \%$ & 5.861 & $>3$ call/day & $14.8 \%$ & \\
\hline
\end{tabular}

Figure 1

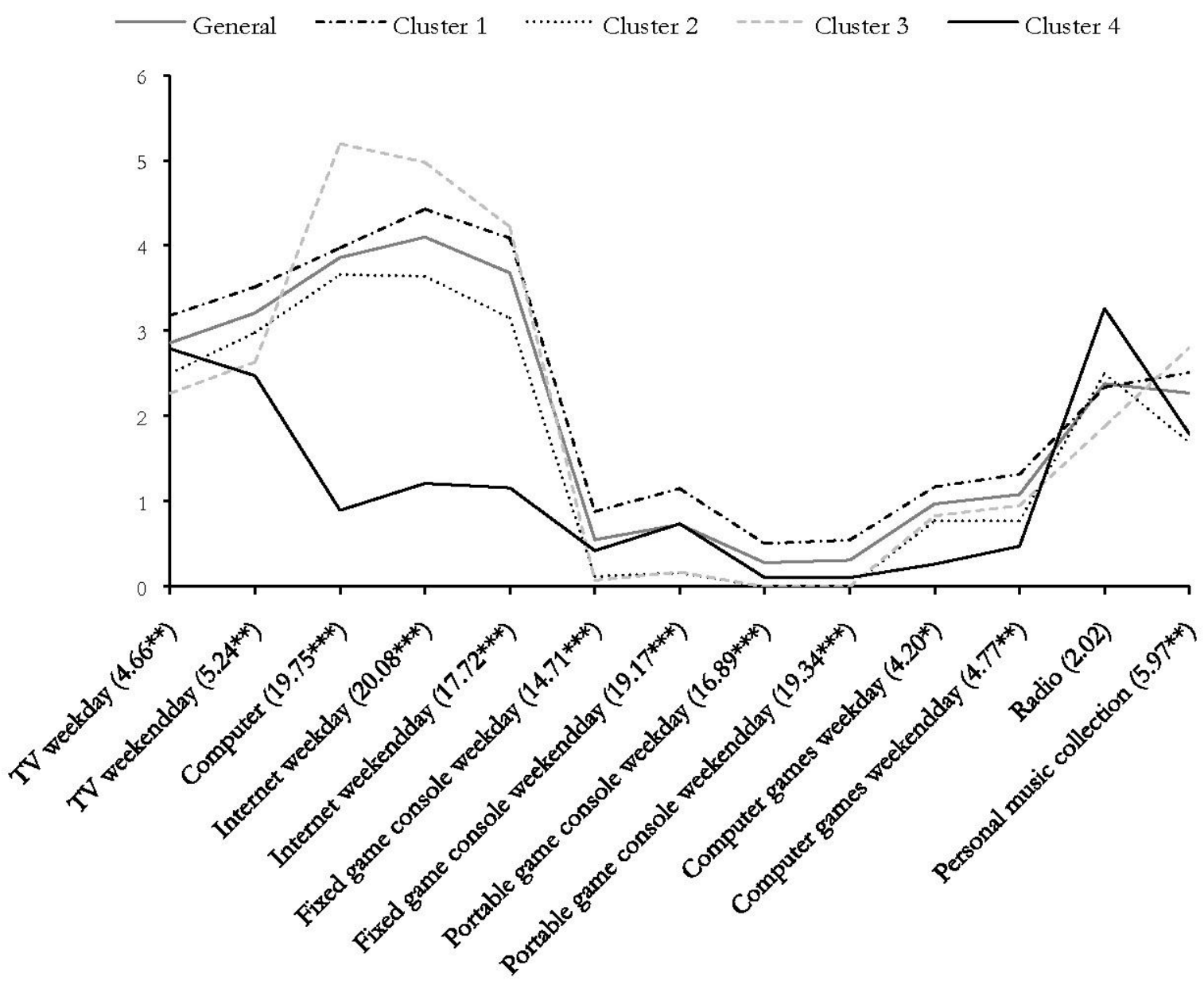


Figure caption: "All $F(3,350)$ are included in the graph descriptions. ${ }^{*} p<.05,{ }^{* *} p<.005,{ }^{* * *} p<$ $.001^{\prime \prime}$ 